\title{
Pitting Corrosion of Thermally Aged Duplex Stainless Steels at Different Temperature for Long Time
}

\author{
Yongqiang Wang ${ }^{a}$, Hao Sun ${ }^{a}$, Junliang $\mathrm{Li}^{a}$, Dandan $\mathrm{Li}^{a}, \mathrm{Na} \mathrm{Li}{ }^{b * \mathbb{C}}$ \\ a School of Materials Science and Engineering, Anhui University of Technology, Maanshan, China; \\ ${ }^{b}$ School of Metallurgical Engineering, Anhui University of Technology, Maanshan, China
}

Received: October 09, 2018; Revised: August 08, 2019; Accepted: October 24, 2019

\begin{abstract}
The pitting corrosion of three duplex steels (DSS), SAF2205, SAF2507, Z3CN20.09M thermally aged at $350-500{ }^{\circ} \mathrm{C}$ for $5500 \mathrm{~h}$ was investigated by the means of electrochemical techniques. The pitting potential $\left(E_{\mathrm{p}}\right)$ of thermally aged $\mathrm{Z3CN} 20.09 \mathrm{M}$ specimens decreased with increasing of ageing temperature, however, the $E_{\mathrm{p}}$ of SAF2205 and SAF2507 thermally aged specimens decreased first and reached the lowest value at $450{ }^{\circ} \mathrm{C}$ and then increased slightly. The electrochemical impedance spectroscopy results are coincident with the potentiodynamic polarisation testing results. The variation in the charge transfer resistance of specimens coincided with the $E_{\mathrm{p}}$ values. There is little influence of low temperature (below $350^{\circ} \mathrm{C}$ ) on resistance to pitting of SAF2205 and SAF2507 DSS. But, the pitting resistance of them degrades drastically ageing at higher temperature above $450{ }^{\circ} \mathrm{C}$. The deterioration in pitting resistance of thermally aged DSS specimens mainly attributes to the precipitation of Cr-rich $\alpha^{\prime}$ phases which affected by temperature markedly. At the range of $350-500{ }^{\circ} \mathrm{C}$, the temperature the higher, the precipitation of $\mathrm{Cr}$-rich $\alpha^{\prime}$ phases the more. The formation of $\mathrm{G}$ phases and the healing process during the long thermal ageing at $500{ }^{\circ} \mathrm{C}$ is the other reasons for the change in pitting resistance.
\end{abstract}

Keywords: Duplex stainless steel, thermal ageing temperature, pitting corrosion, $\alpha^{\prime}$ phase, healing.

\section{Introduction}

Duplex stainless steels (DSSs), which are characterized by austenite-ferrite dual microstructure, are widely used in many applications such as oil, petrochemical, marine and nuclear power industries due to their outstanding corrosion resistance, higher resistance to stress corrosion cracking and excellent mechanical properties ${ }^{1-6}$. However, they will be subjected to thermal aging embrittlement and sensitization when they are exposed to the temperature range of 320 $-1000^{\circ} \mathrm{C}$ mainly due to the formation of several undesirable precipitates such as $\alpha^{\prime}, \mathrm{G}, \mathrm{M}_{23} \mathrm{C}_{6}, \sigma, \chi$, etc in ferrite phase $\mathrm{e}^{2,7-10}$. These precipitated phases not only severely decrease the toughness of steels but also negatively impact corrosion resistance, especially localised corrosion ${ }^{11-13}$.

Pitting corrosion, the localized dissolution of a passivated metal in the presence of a solution of certain anionic species, is a major cause of failure of stainless steels owing to pits perforation or acting as an initiation site for cracking ${ }^{14}$. Generally, any factor whose can bring the defects in passive film or cause chemical or physical heterogeneity at the surface, such as inclusions, second phase particles, solutesegregated grain boundaries, flaws, mechanical damage, or dislocations, will be considered as the possible reasons for pitting corrosion ${ }^{4,15-19}$. Thermal aging embrittlement induced by the spinodal decomposition of ferrite phases into coherent Cr-enriched $\alpha^{\prime}$ and the precipitation of G-phase in ferrite can also degrade the pitting resistance of DSS. In the past decades, many works have been done to investigate the localized corrosion behaviors of thermally aged DSS. Some

*e-mail: linaustb@163.com of them reported the mechanism of the effect of thermal aging on pitting corrosion or intergranular corrosion ${ }^{12,20}$. In others, the researches on the chemical or electrochemical of thermally aged DSS only were used to evaluate the material degradation induced by thermal aging ${ }^{21,22}$. However, on one hand, a few attempts have been taken to discuss the effect of different thermal aging temperature on the pitting resistance of them, especially for the DSS thermally aged for a long time. Temperature is one of the most important factors for the thermal aging embrittlement of DSS and can certainly affect the pitting corrosion. On the other hand, duplex stainless steels which used for the primary coolant pipe of nuclear power plants are long-term serviced at the high temperature and pressure water containing $\mathrm{Cl}^{-}, \mathrm{Li}^{+}$and $\mathrm{BO}_{3}{ }^{3-}$ environment that could cause thermal aging embrittlement and corrosion of pipe. Localised corrosion is one of the most main breakages of primary coolant pipe ${ }^{23}$. The research on the effect of temperature on the pitting corrosion of thermally aged DSS is helpful for the evaluation of safety working of nuclear power plant.

The aim of this work is to examine the effect of thermal aging temperature on the pitting corrosion of duplex stainless steel. Three SAF2205, SAF2507 and Z3CN20.09M DSS are adopted to make efforts to elucidate the mechanism of the effect of temperature on pitting corrosion conveniently. Pitting behaviors of thermally aged specimens were investigated by using potentiodynamic polarisation and electrochemical impedance spectroscopy technologies. There are differences in chemical composition and microstructure between SAF2205, SAF2507 and Z3CN20.09M DSS. The investigation was performed after thermal aging at $350-500{ }^{\circ} \mathrm{C}$ temperatures 
for $5500 \mathrm{~h}$. The investigation results of different DSS can more convincing.

\section{Experimental Details}

\subsection{Materials}

The chemical compositions of the studied three duplex stainless steels, SAF2205, SAF2507 and Z3CN20.09M are listed in Table 1. These DSSs were annealed at 1050 ${ }^{\circ} \mathrm{C}, 1100{ }^{\circ} \mathrm{C}, 1180{ }^{\circ} \mathrm{C}$ for $0.5 \mathrm{~h}$, respectively, for solid solution first followed by water quenching. And then, they were thermally aged for $5500 \mathrm{~h}$ at the temperature $350^{\circ} \mathrm{C}$, $450{ }^{\circ} \mathrm{C}, 500{ }^{\circ} \mathrm{C}$ respectively. The different size specimens cut from the thermally aged DSS samples were used to the microstructure examination, microhardness measurement and pitting corrosion investigation.

\subsection{Microstructures examination and microhardness measurement}

The DSS specimens with a size of $10 \mathrm{~mm} \times 10 \mathrm{~mm} \times$ $10 \mathrm{~mm}$ are used for the microstructure examination and microhardness measurement. The specimens were abraded using silicon carbide abrasive paper to $2000 \#$ and then polished by diamond paste with a size of $1.5 \mu \mathrm{m}$. Finally, the specimens were electrochemically etched for 10-20 s in a $20 \mathrm{wt} \% \mathrm{NaOH}$ solution in distilled water with a direct voltage of $3 \mathrm{~V}$ in order to differentiate the ferrite, austenite or other phases. The microstructures of the specimens were observed by optical microscopy (OM) and transmission electron microscopy (TEM). The ferrite content in specimens was calculated on 20 optical measurements for each specimen by using quantitative metallography analysis software (Image-Pro Plus6.0). The microhardness of ferrite and austenite phases in the DSS specimens was measured with a WOLPERT 401MVD microhardness instrument.

\subsection{Electrochemical measurements}

DC electrochemical measurements were performed with a $\mathrm{CHI}$ electrochemical workstation ( $\mathrm{CH}$ Instruments). The three DSS specimens with a size of $10 \mathrm{~mm} \times 10 \mathrm{~mm} \times 3 \mathrm{~mm}$ are used as working electrodes. They were prepared by spot welding a copper wire onto one side of each specimen and then embedded in epoxy resin with an exposure area of 1 $\mathrm{cm}^{2}$. The reference electrode is a saturated calomel electrode (SCE) and a Pt foil is used as the auxiliary electrode.
Pitting corrosion tests were carried out in a $0.5 \mathrm{~mol} / \mathrm{L}$ $\mathrm{NaCl}$ solution at constant temperature $\left(30 \pm 1{ }^{\circ} \mathrm{C}\right)$ by potentiodynamic anodic polarization and electrochemical impedance spectroscopy (EIS) techniques to evaluate the pitting potential $\left(E_{\mathrm{p}}\right)$ and the passive layer breakdown of the specimens, respectively. $E_{\mathrm{p}}$ is defined as the potential at which the current increases sharply from the passive current level ${ }^{14}$

Before testing, the working electrodes were immersed in the test solution for $30 \mathrm{~min}$ until the steady-state open circuit potential $\left(E_{\text {ocp }}\right)$ was reached. In addition, a potential sweep was applied in the anodic direction at a scan rate of $20 \mathrm{mV} / \mathrm{min}$ from $-400 \mathrm{mV}$ (SCE) to an appropriate value. EIS measurements were carried out using the frequency range of $100 \mathrm{kHz}$ to $0.01 \mathrm{~Hz}$ at the $E_{\text {ocp }}$. Amplitudes of all sinusoids were equal to $10 \mathrm{mV}$ rms. The EIS results were interpreted using an equivalent circuit. The characteristic parameter values of these elements in an equivalent circuit were then obtained directly by fitting the experimental curves using the Zview Version 3.1 ${ }^{\circledR}$ software.

\section{Results and Discussions}

\subsection{Microstructures of thermally aged DSS specimens}

Figure 1 shows the microstructures of solid solution and thermally aged SAF2205, SAF2507, Z3CN20.09M specimens, which consist of austenite (gray) and ferrite (dark) phases. No other phase is apparently observed in these specimens aged at the temperature range of $350-450{ }^{\circ} \mathrm{C}$. Moreover, the volume fraction of ferrite phase in thermally aged specimens is almost equal to that of solid solution ones (seen in Figure 2). Thermal aging embrittlement of DSS are mainly induced by the formation of $\alpha$ ' phase by ferrite spinodal decomposition and the precipitation of G-phase in ferrite. These precipitates are very small, moreover, $\alpha$ ' phase is coherent or semicoherent with ferrite matrix ${ }^{10}$. On the other hand, the other transformations, for instance, $\sigma, \chi$ precipitation or $\alpha \rightarrow \gamma$ don't happen at the temperature range of $350{ }^{\circ} \mathrm{C}$ to $500{ }^{\circ} \mathrm{C}$ according to the thermodynamics of phase transition and phase diagrams of the three $\mathrm{DSS}^{2}$. So, there is hardly any influence of thermal ageing on ferrite content, size and morphology. However, some precipitates can be found in the aged SAF2205, SAF2507 specimens at $500{ }^{\circ} \mathrm{C}$ (Figure 1d) and a few carbide $\mathrm{M}_{23} \mathrm{C}_{6}$ can form in the aged $\mathrm{Z3CN} 20.09 \mathrm{M}$ specimen at

Table 1. Chemical compositions of three duplex stainless steels (wt.\%)

\begin{tabular}{lcccccccccc}
\hline \multirow{2}{*}{ Type } & \multicolumn{10}{c}{ Elements(wt\%) } \\
\cline { 2 - 11 } & $\mathbf{C}$ & $\mathbf{S i}$ & $\mathbf{M n}$ & $\mathbf{P}$ & $\mathbf{S}$ & $\mathbf{C r}$ & $\mathbf{N i}$ & $\mathbf{M o}$ & $\mathbf{N}$ & $\mathbf{F e}$ \\
\hline SAF2205 & 0.023 & 0.380 & 1.35 & 0.026 & 0.001 & 22.07 & 4.83 & 2.37 & 0.190 & balance \\
SAF2507 & 0.023 & 0.497 & 1.55 & 0.020 & 0.001 & 25.15 & 7.37 & 4.35 & 0.250 & balance \\
Z3CN20.09M & 0.027 & 1.270 & 1.13 & 0.023 & 0.0009 & 20.19 & 8.92 & 0.21 & 0.031 & balance \\
\hline
\end{tabular}


(a)

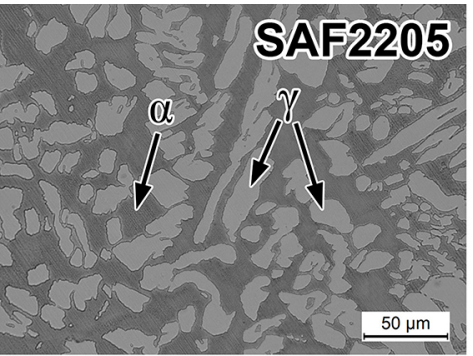

(b)

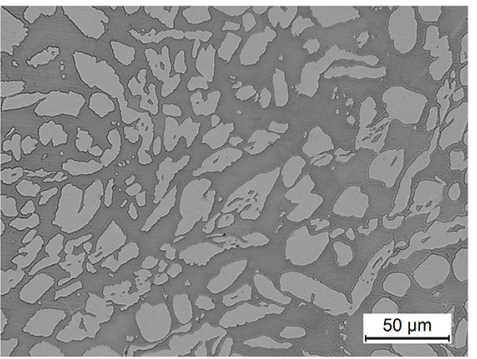

(c)

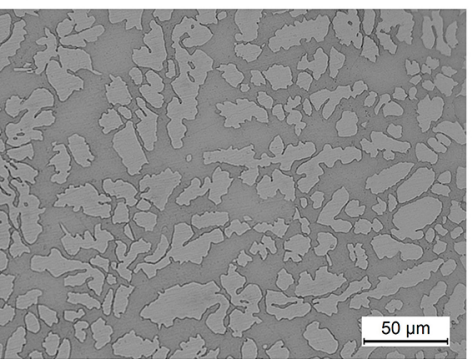

(d)

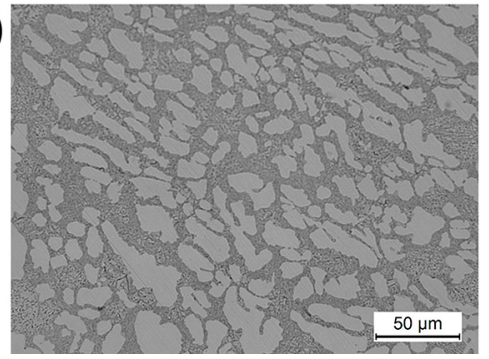

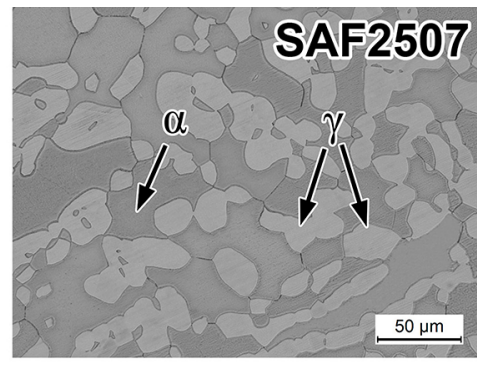
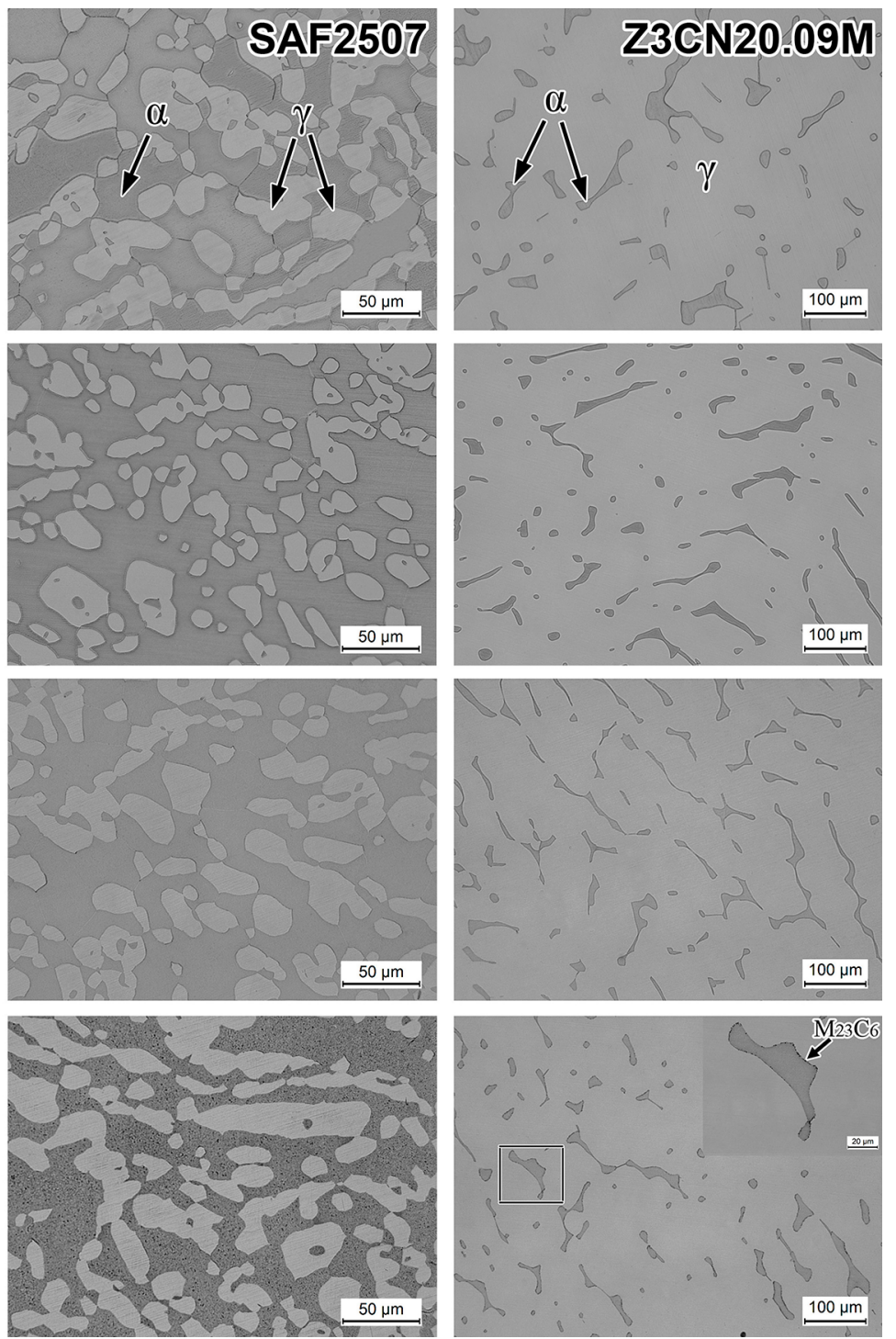

Figure 1. Microstructures of DSS specimens solid solution (a) and thermally aged for $5500 \mathrm{~h}$ at different temperature (b) $350^{\circ} \mathrm{C}$, (c) $450^{\circ} \mathrm{C}$, (d) $500^{\circ} \mathrm{C}$

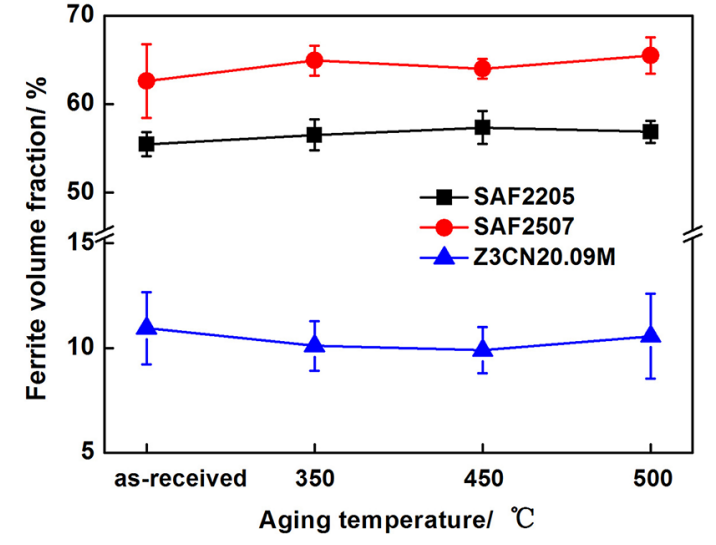

Figure 2. Ferrite volume fraction of specimens thermally aged at different temperature
$500{ }^{\circ} \mathrm{C}$ on the basis of phase diagram calculated using Thermo-Calc software ${ }^{9}$.

In order to detect the changes in microstructures of ferrite in thermally aged DSS specimens, the microstructures after thermal ageing were examined by Transmission Electron Microscopy (TEM). Figure $3 a$ and $b$ show the bright-field TEM images of Z3CN20.09M specimens thermally aged at $450{ }^{\circ} \mathrm{C}$ and $500{ }^{\circ} \mathrm{C}$ respectively. The mottled contrast in the ferrite phase could clearly be observed in the specimen aged at $450{ }^{\circ} \mathrm{C}$ (Figure $3 \mathrm{a}$ ). Small particles of $\alpha^{\prime}$ phases and $\mathrm{G}$ phases of a few nanometer in size are visible in ferrite phase of the specimens aged at $500{ }^{\circ} \mathrm{C}$ (Figure $3 \mathrm{~b}$ ). The mottled contrast in the ferrite phase has been attributed to the compositional 
fluctuation induced by spinodal decomposition of ferrite phase into Fe-rich $\alpha$ and Cr-rich $\alpha^{\prime 24}$. The observation performed on Z3CN20.09M DSS aged at $500{ }^{\circ} \mathrm{C}$ indicates that in this specimen condition $\alpha \rightarrow \alpha+\alpha^{\prime}$ phase separation takes place via a nucleation and growth mechanism ${ }^{25}$. Similar microstructures were observed for other thermally aged specimens (SAF 2205 and SAF2507) at $450{ }^{\circ} \mathrm{C}$ and $500{ }^{\circ} \mathrm{C}$ indicating that spinodal decomposition of ferrite in the three DSS takes place at below temperatures $500{ }^{\circ} \mathrm{C}$. Nevertheless, $\alpha^{\prime}$ phases precipitate in ferrite of thermally aged DSS specimens at $500{ }^{\circ} \mathrm{C}$ by nucleation and growth.

\subsection{Microhardness of thermally aged DSS specimens at different temperature}

Figure 4 displays the microhardness of different DSS specimens. One can see that there is no change in the microhardness of austenite phase with ageing period and there is little scattering in the hardness values. However, the ferrite hardness is found to change substantially with ageing time. With increasing thermal ageing temperature the hardness of ferrite phase increased first and reached the highest value at $450{ }^{\circ} \mathrm{C}$ and then decreased. Based on these results, the increase in the hardness of ferrite phase can be used to represent the degree of embrittlement in thermally aged DSS, although, it cannot exactly represent the overall embrittlement of the material because of the other effects, e.g., ferrite fraction and its distribution ${ }^{24}$. However, it reflects the embrittlement of the ferrite phase directly only which is the main cause of embrittlement observed in the material. The hardness results of ferrite indicate that the most serious thermal ageing embrittlement of all the three DSS specimens has taken place at temperature $450{ }^{\circ} \mathrm{C}$. Comparing with $450{ }^{\circ} \mathrm{C}$, the decrease in hardness of ferrite in specimens aged at $500{ }^{\circ} \mathrm{C}$ might mainly attribute to the formation of $\alpha^{\prime}$ phase via nucleation and growth but not by spinodal decomposition of ferrite. Similar to the present result of hardness variation with ageing temperature was also reported by Mats Hättestrand et $\mathrm{a}^{25}$. The other possible reason is the healing or desensitisation phenomenon occurring in the ferrite phase, whereby, the $\mathrm{Cr}$ diffusion reduces or completely eliminates the concentration gradient of $\mathrm{Cr}^{26,27}$. Both of these above processes can cause the reduction of interface stress of $\alpha^{\prime}$ and $\alpha$ phase.

\subsection{Potentiodynamic anodic polarisation curves of thermally aged DSS specimens}

Figure 5 shows the polarisation curves of different SAF2205, SAF2507, Z3CN20.09M specimens. Based on the polarisation curves, the variation in pitting potential $\left(E_{\mathrm{p}}\right)$ for the different specimens can be found, as shown in Figure 6. One can see that the $E_{\mathrm{p}}$ of the solid solution SAF2507 specimen is the highest, while the $E_{\mathrm{p}}$ of the solid solution Z3CN20.09M specimen is the lowest. Besides, the $E_{\mathrm{p}}$ of aged Z3CN20.09M specimen became less positive than that of solid solution ones and decreased with the increase of thermal ageing temperature. However, the $E_{\mathrm{p}}$ of aged SAF2205 and
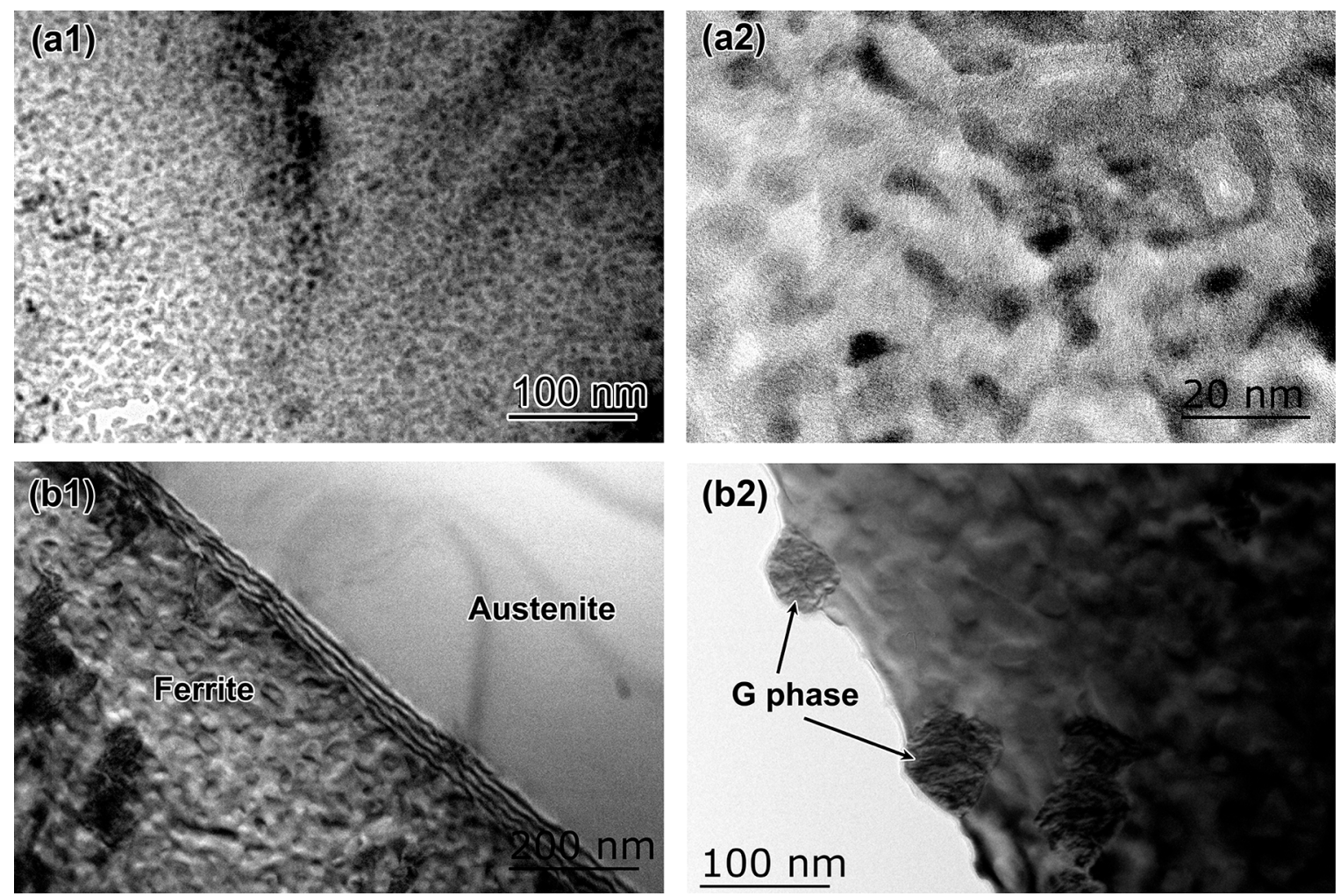

Figure 3. Bright-field TEM micrographs for Z3CN20.09M DSS specimens aged at different temperature (a) $450{ }^{\circ} \mathrm{C}$ and (b) $500{ }^{\circ} \mathrm{C}$ 

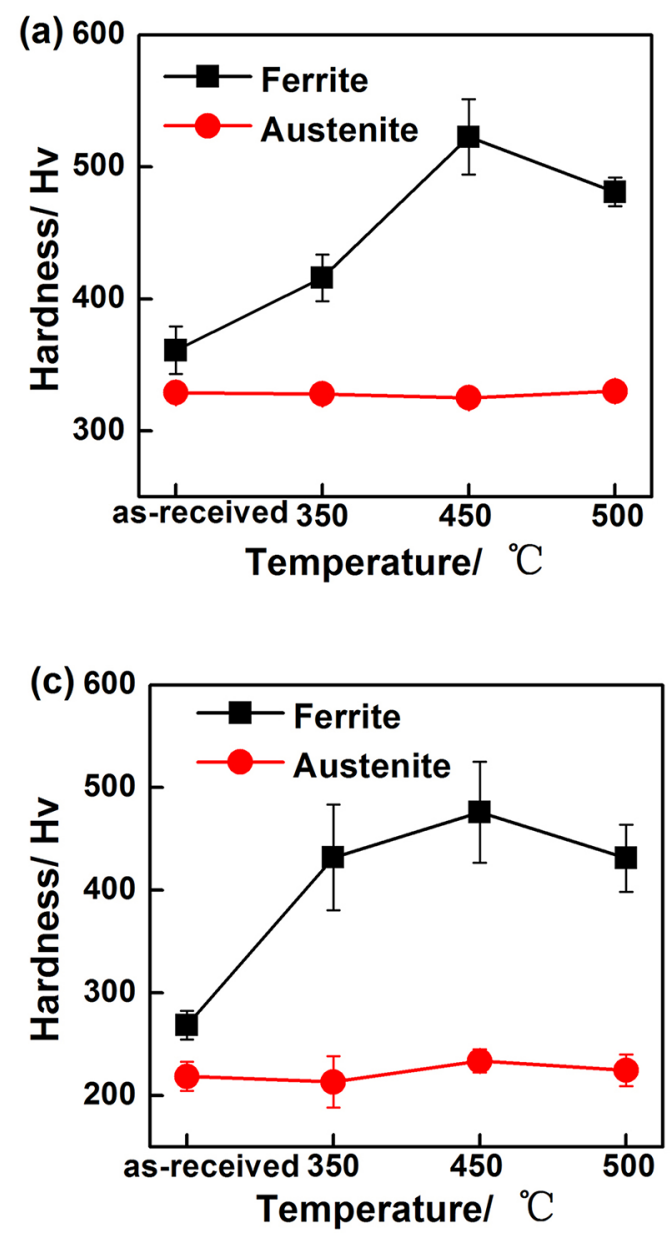
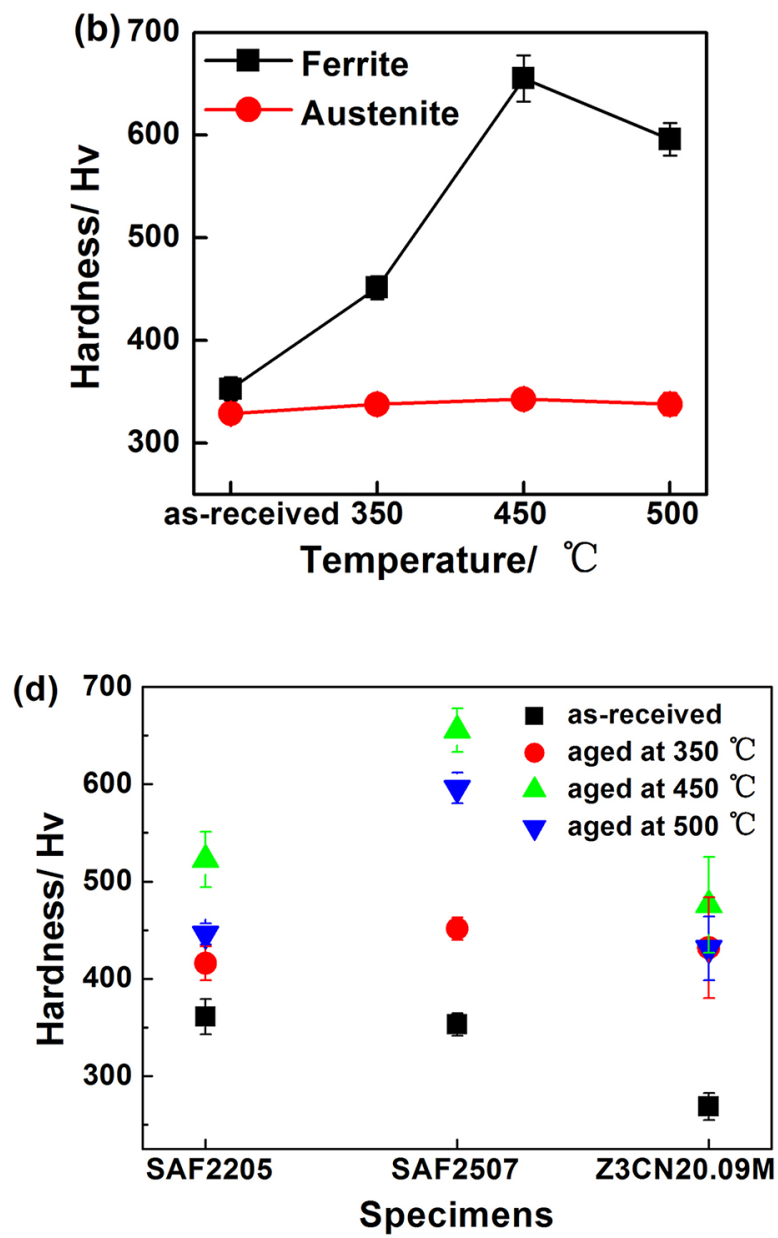

Figure 4. The changes in microhardness of three thermally aged DSS specimens with thermal ageing temperature (a) SAF2205, (b) SAF2507, (c) Z3CN20.09M and (d) hardness of ferrite in different thermally aged DSS specimens

SAF2507 specimens decreased firstly and then increased slightly with thermal ageing temperature (Figure 6a). The lowest $E_{\mathrm{p}}$ was found in SAF2205 and SAF2507 specimens thermally aged at $450^{\circ} \mathrm{C}$. Moreover, the $E_{\mathrm{p}}$ of Z3CN20.09M specimen aged at $450{ }^{\circ} \mathrm{C}$ and $500{ }^{\circ} \mathrm{C}$ is higher than that of the SAF2205 and SAF2507 specimens aged at the same temperature. Among the three DSS specimens thermally aged at $500{ }^{\circ} \mathrm{C}$, The $E_{\mathrm{p}}$ of SAF2507 specimen is the lowest (Figure 6b). The micrographics of different Z3CN20.09M specimens after the electrochemical tests are shown in Figure 7. The number of pits in specimens increased with ageing temperature. Moreover, the morphology of pits is different significantly. The pits in the solid solution specimen formed at the interface of ferrite/austenite boundary frequently (Figure 7a). However, abundant pits were found in the ferrite phase in thermally aged specimens especially in ones aged at $500{ }^{\circ} \mathrm{C}$ (Figure $7 \mathrm{~d}$ ).

Thermal ageing induces the precipitation of $\mathrm{Cr}$-rich $\alpha^{\prime}$ phases in ferrite and brings the Cr-depleted zones around them. The interface between $\mathrm{Cr}$-enriched $\alpha^{\prime}$ phase and $\mathrm{Cr}$ depleted zone could become the preferential sites for pits initiation, subsequently, pits grew in ferrite ${ }^{13,28,29}$. The more the precipitation of $\alpha^{\prime}$ phases and Cr-depleted zones, the worse the pitting resistance of DSS specimens revealing by the lower $E_{\mathrm{p}}$ value. Thermal ageing embrittlement of stainless steel is mainly decided by ageing time, ageing temperature, chemical composition and ferrite phase fraction. At certain range of temperature, on the one hand, the higher the thermal ageing temperature, the more the Cr-enrich $\alpha^{\prime}$ phase. On the other hand, the higher the $\mathrm{Cr}$ element content and the more the ferrite phase fraction, the more the precipitation of $\mathrm{Cr}$-enrich $\alpha^{\prime}$ phase and $\mathrm{Cr}$-depleted zone. So the $E_{\mathrm{p}}$ value of the three DSS specimens decreased with increasing of thermal ageing temperature until $450^{\circ} \mathrm{C}$. Meanwhile, the $E_{\mathrm{p}}$ of aged SAF2507 specimen is lower than that of SAF2205 and Z3CN20.09M specimens at the same ageing temperature, for instance $450^{\circ} \mathrm{C}$ and $500{ }^{\circ} \mathrm{C}$, due to the highest $\mathrm{Cr}$ content and the most ferrite phase in SAF2507 DSS. It is worth noting that the smooth increase in $E_{\mathrm{p}}$ of SAF2205 and SAF2507 specimens aged at $500{ }^{\circ} \mathrm{C}$ is maybe due to a healing or desensitization process ${ }^{26,27}$, which is caused by the chromium diffusion reducing or eliminating the gradient of concentration of this element and the interface of $\mathrm{Cr}$-enrich $\alpha^{\prime}$ phase and $\mathrm{Cr}$-depleted zones. The decrease 

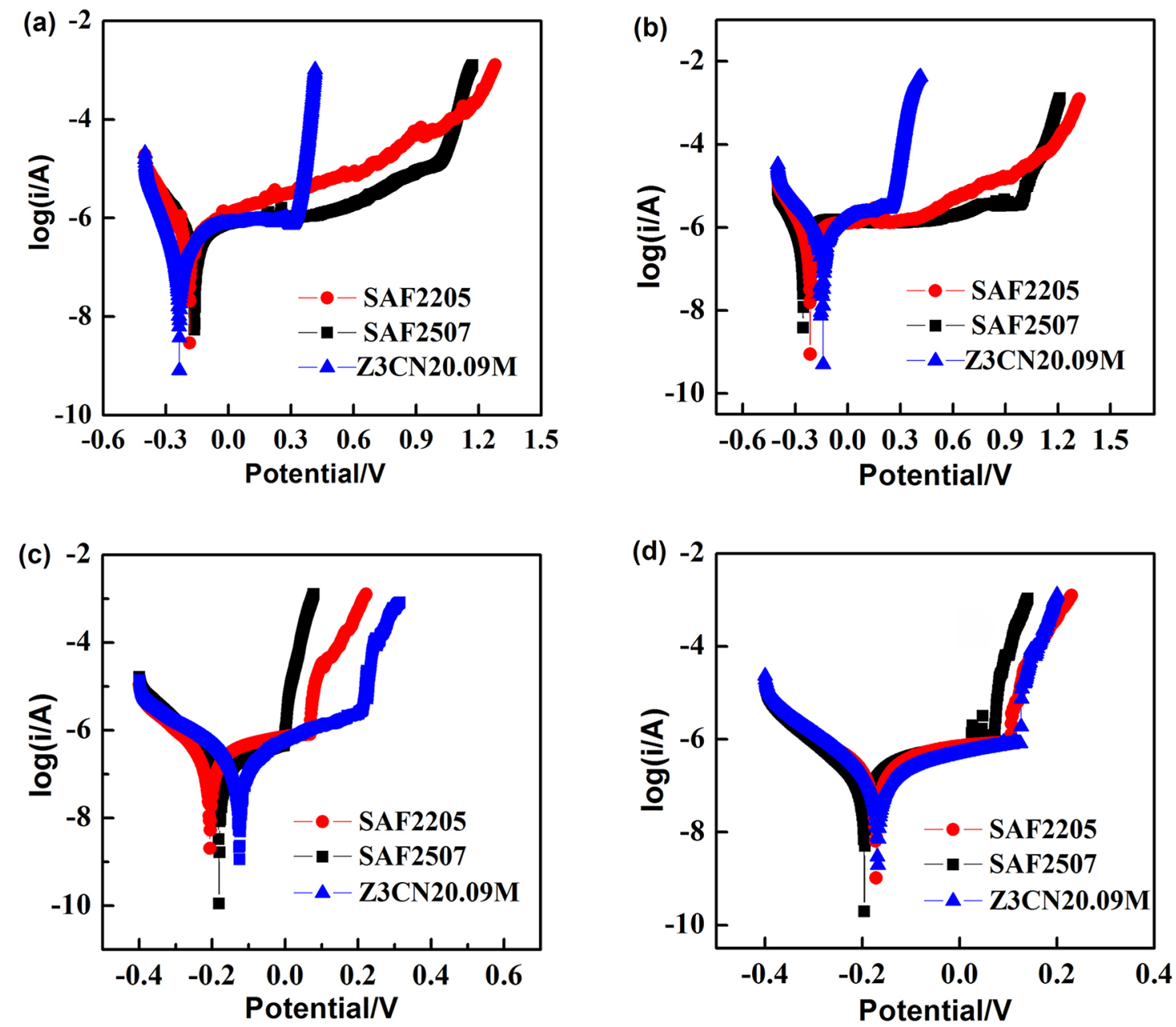

Figure 5. Polarisation curves of DSS specimens aged at different temperature (a) solid solution, (b) $350^{\circ} \mathrm{C}$, (c) $450^{\circ} \mathrm{C}$, (d) $500^{\circ} \mathrm{C}$
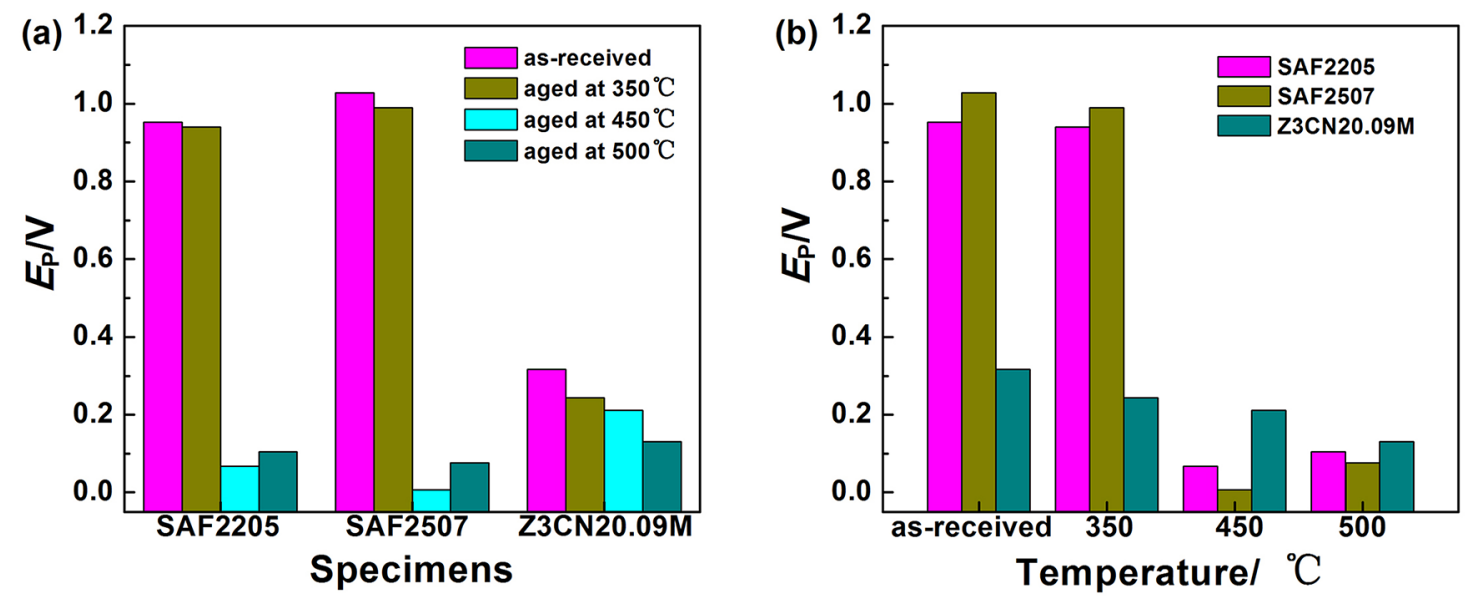

Figure 6. Pitting potential of (a) different thermally aged DSS specimens and (b) different thermal aging temperature 

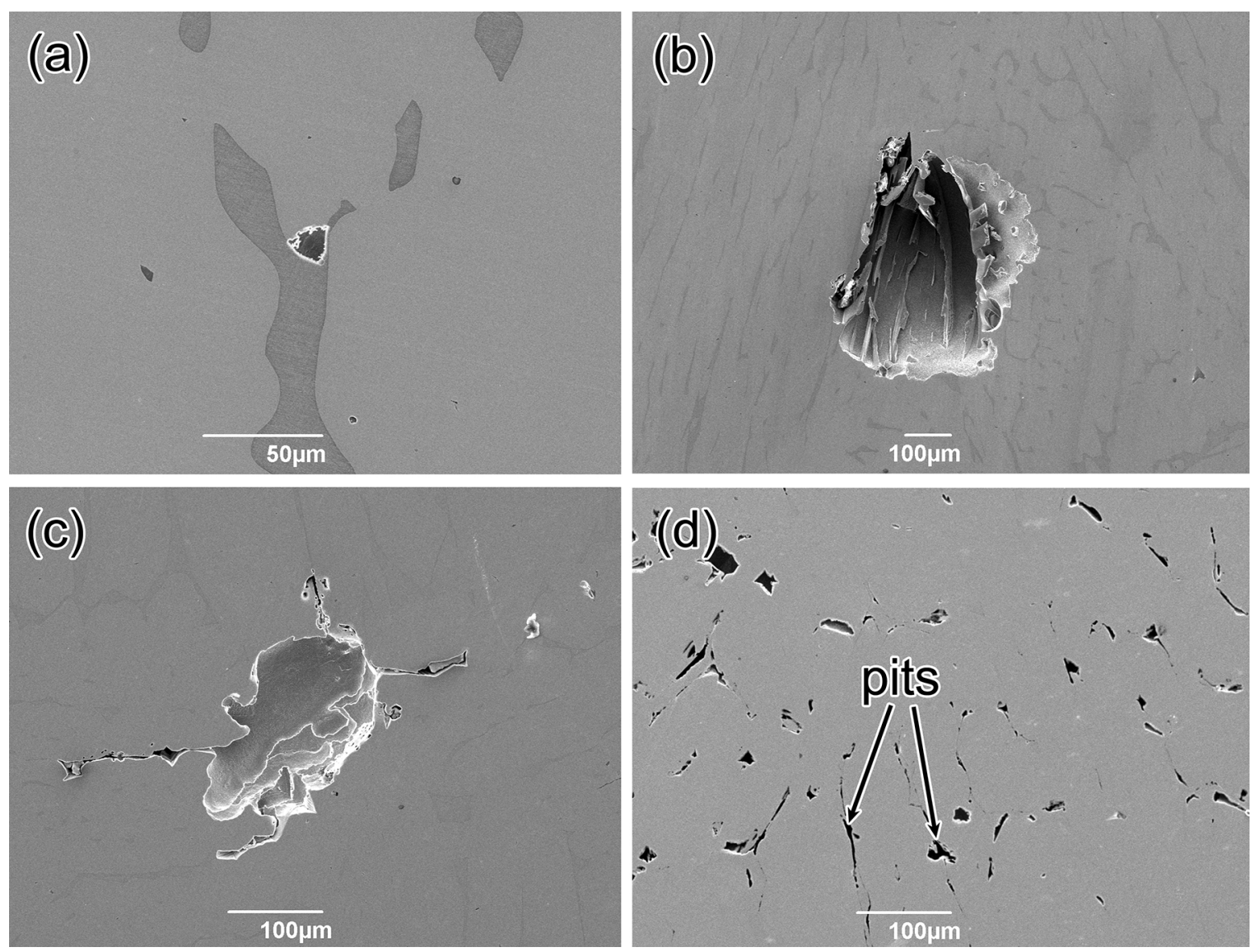

Figure 7. The micrographics of different $\mathrm{Z3CN} 20.09 \mathrm{M}$ specimens after the electrochemical tests (a) solid solution, (b) $350^{\circ} \mathrm{C}$, (c) $450^{\circ} \mathrm{C}$, (d) $500^{\circ} \mathrm{C}$

in $E_{\mathrm{p}}$ of $\mathrm{Z3CN} 20.09 \mathrm{M}$ specimens aged at $500^{\circ} \mathrm{C}$ should be ascribed to the formation of considerable $\mathrm{G}$ phases in ferrite and few $\mathrm{M}_{23} \mathrm{C}_{6}$ carbides on the $\alpha / \gamma$ boundary.

\subsection{EIS results of thermally aged DSS specimens}

Figure 8 shows the EIS results of specimens thermally aged at different temperature and different DSS specimens. The distinct differences of semicircle arcs for different specimens existing in the Nyqusit plots can be found in the figure. In general, the decrease in the semicircle arc radius is indicated by the decrease in the charge transfer resistance $\left(R_{\mathrm{ct}}\right)$ value which is inversely proportional to the corrosion rate of the system. The semicircle arc radius of $Z 3 \mathrm{CN} 20.09 \mathrm{M}$ specimen decreased with thermal ageing temperature. It means that electric charges in these specimens aged at high temperature transfer easily through the passive film of specimens. However, the semicircle arc radius of SAF2205 and SAF2507 specimens decreased first and then increased with thermal aging temperature. The lowest values of semicircle arc radius were found in these specimens aged at $450{ }^{\circ} \mathrm{C}$.

An equivalent electrical circuit was designed as a best-fit to the EIS experimental results and is displayed in Figure 9, which consists of the arrangement of $\left[R_{\mathrm{s}}\left(\mathrm{CPE} \| R_{\mathrm{ct}}\right)\right]$ elements, where $R_{\mathrm{s}}$ is the solution resistance and CPE is the constant phase in parallel connection with $R_{\mathrm{ct}}$ which is the charge transfer resistance at the interface. All the fitting parameters of the impedance plots are shown in Table 2. From the table, the $R_{\mathrm{ct}}$ value of Z3CN20.09M specimen decreased with the increase of thermal ageing temperature and reached the lowest value at $500{ }^{\circ} \mathrm{C}$. While, the $R_{\mathrm{ct}}$ of SAF2205 and SAF2507 specimens decreased first and then increased slightly with thermal ageing temperature, and reached the lowest value in these specimens aged at $450^{\circ} \mathrm{C}$. Moreover, the $R_{\mathrm{ct}}$ value of SAF 2507 specimens thermally aged at $350{ }^{\circ} \mathrm{C}$ is the highest among the three DSS specimens. However, the $R_{\mathrm{ct}}$ values of SAF2507 specimens thermally aged at $450{ }^{\circ} \mathrm{C}$ and $500{ }^{\circ} \mathrm{C}$ are both lower than those of SAF2205 and Z3CN20.09M specimens.

The precipitation of Cr-rich $\alpha^{\prime}$ phase induced by the thermal ageing embrittlement brings the segregation of $\mathrm{Cr}$ element that is one of the most important factors for the passive film on the surface of stainless steels. The segregation of $\mathrm{Cr}$ element makes passive film less protective. The more serious the thermal ageing, the greater the segregation of $\mathrm{Cr}$ element, therefore, the worse the pitting resistance is. Because the most serious thermal ageing embrittlement occurs in the SAF2507 specimens thermally aged at $450{ }^{\circ} \mathrm{C}$ due to the highest $\mathrm{Cr}$ content, the most ferrite fraction and higher temperature, so the worst pitting resistance was performed 

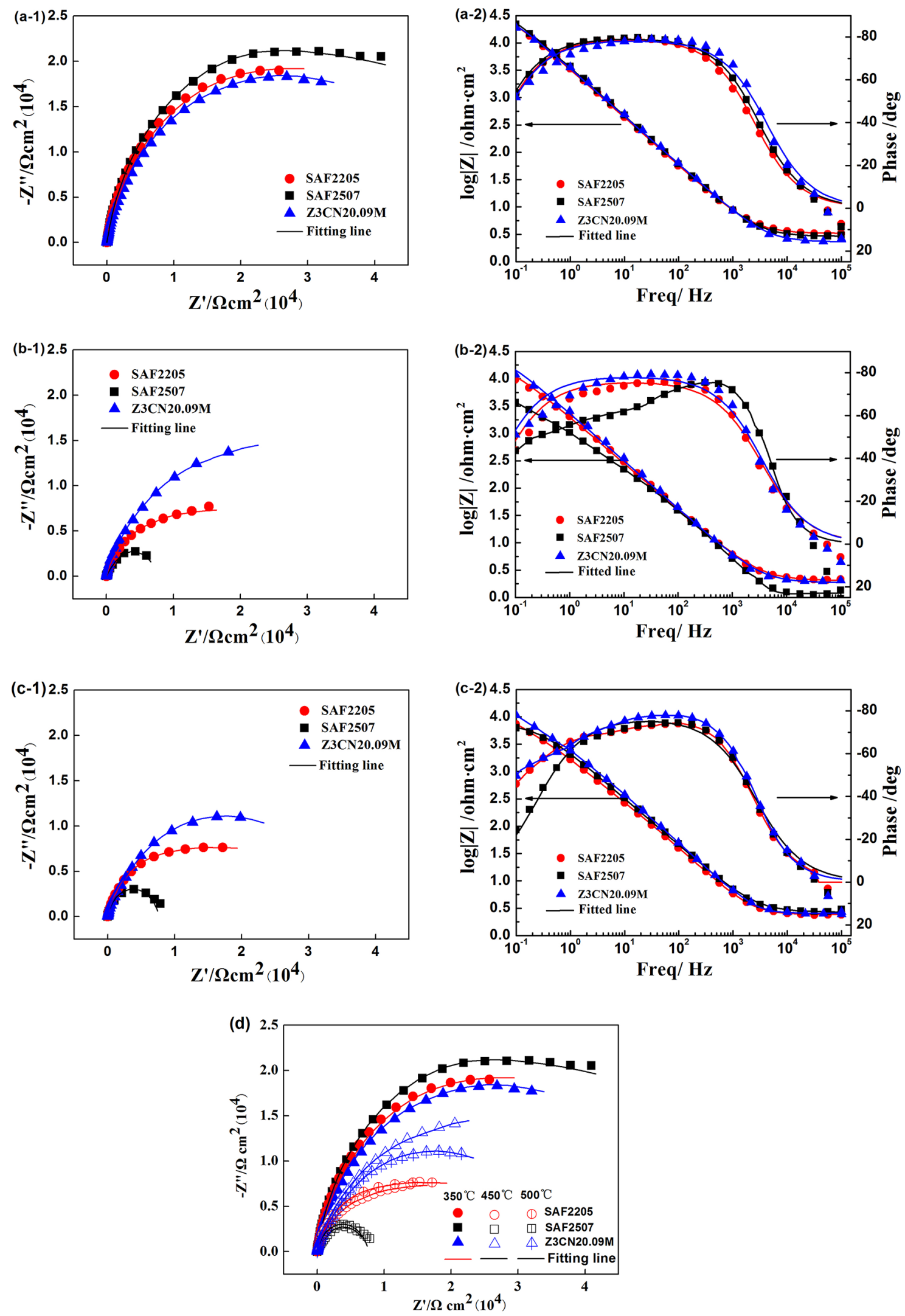

Figure 8. Nyqusit plots for specimens thermally aged at different temperature (a) $350^{\circ} \mathrm{C}$, (b) $450^{\circ} \mathrm{C}$, (c) $500^{\circ} \mathrm{C}$ and (d) different DSS specimens 


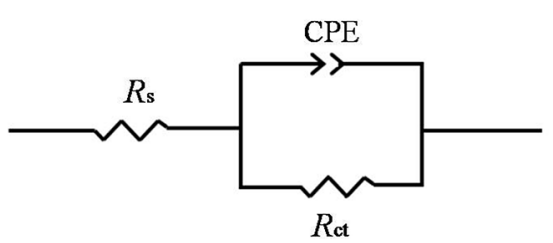

Figure 9. Equivalent circuit for fitting experimental Nyquist impedance plots

revealing by the lowest $R_{\mathrm{ct}}$ value, as shown in Table 2 . The increase in $R_{\mathrm{ct}}$ of SAF2205 and SAF2507 specimens thermally aged at $500{ }^{\circ} \mathrm{C}$ should be attributed to the healing which reduced or alleviated the segregation of $\mathrm{Cr}$ element.

\subsection{Mechanism of the effect of thermal temperature on pitting}

The corrosion resistance of stainless steels is closely related to the passive film on their surface, which is mainly determined by alloy composition, electrolyte media, and condition of the material ${ }^{4,14}$. Cr is the most important element in conferring passivity to stainless steels ${ }^{4}$ and Mo is another very important element for improving the pitting resistance of stainless steels ${ }^{30,31}$. The pitting potential of stainless steels correspondingly becomes more positive remarkably, as $\mathrm{Cr}$ and Mo concentration increases ${ }^{14,32}$. Therefore, the highest $E_{\mathrm{p}}$ values that indicating the best pitting resistance are obtained in the solid solution SAF2507 specimens for the highest $\mathrm{Cr}$ and Mo content of them. The lowest $E_{\mathrm{p}}$ values are found in the solid solution Z3ZN20.09M specimens due to the fewest $\mathrm{Cr}$ and Mo element (Figure 5a, Figure 6b).

The condition of stainless steel has been changed when they are subjected to thermal ageing for long time. Thermal ageing brings the segregation of $\mathrm{Cr}$ due to the precipitation of Cr-rich $\alpha^{\prime}$ phases and the formation of Cr-depleted zones around $\alpha^{\prime}$ phases. So the resistance to pitting of DSS becomes poor with thermal ageing development. $G$ phases also precipitate in ferrite during thermal ageing, especially for high ageing temperature and long ageing time. Although, $\mathrm{G}$ phases enriched in $\mathrm{Ni}$ and $\mathrm{Si}$ elements which are not sensitive to pitting corrosion will not obviously induce pitting themselves ${ }^{4,10}$, the pitting resistance of thermally aged DSS might be affected negatively by the precipitation of them due to the stress of $\mathrm{G} / \alpha$ ferrite interface and the $\mathrm{Cr}$ depletion adjacent to the G-phase precipitates ${ }^{12,24}$. Considerable G phases precipitated in ferrite of $\mathrm{Z3CN} 20.09 \mathrm{M}$ specimen aged at $500{ }^{\circ} \mathrm{C}$ due to higher Ni content, as shown in Figure 3 . Thus, the $E_{\mathrm{p}}$ still decreased when ageing temperature increased to $500^{\circ} \mathrm{C}$ although healing occurred in thermally aged $\mathrm{Z3CN} 20.09 \mathrm{M}$ specimens too. Another reason for the decrease in $E_{\mathrm{p}}$ of the aged $\mathrm{Z} 3 \mathrm{CN} 20.09 \mathrm{M}$ specimen at $500{ }^{\circ} \mathrm{C}$ is some the precipitation of $\mathrm{M}_{23} \mathrm{C}_{6}$ carbide on the boundary of $\alpha / \gamma$, as shown in Figure $1 d^{29}$.

Possible healing mechanisms for DSSs thermally aged in the spinodal decomposition temperature range are: 1 . back diffusion of $\mathrm{Cr}$ atoms from $\alpha$ phase to $\mathrm{Cr}$-depleted zone and 2. diffusion of $\mathrm{Cr}$ atoms from the austenite to $\mathrm{Cr}$-depleted zone ${ }^{33}$. High temperature can make the back diffusion of $\mathrm{Cr}$ atoms effective. Healing is also directly related with the composition of DSS especially Cr content and ferrite phase fraction. High $\mathrm{Cr}$ content and ferrite fraction are propitious to improve the diffusion of $\mathrm{Cr}$ atoms that are not only in ferrite matrix but also austenite to Cr-depleted zone, so the effective healing was found in the thermally aged SAF2205 and SAF2507 specimens with higher $\mathrm{Cr}$ content and ferrite fraction at $500{ }^{\circ} \mathrm{C}$ revealing by the increase of $E_{\mathrm{p}}$. For the ineffective healing occurring in the $\mathrm{Z3CN} 20.09 \mathrm{M}$ specimens due to the less ferrite phase and low $\mathrm{Cr}$ content did not bring positively influence on pitting resistance enough, hence, the decrease in $E_{\mathrm{p}}$ of these specimens aged at $500{ }^{\circ} \mathrm{C}$ was still achieved.

\section{Conclusions}

(1) Pitting corrosion of SAF2205, SAF2507 and $\mathrm{Z3CN} 20.09 \mathrm{M}$ duplex stainless steels is affected by thermal ageing temperature. The pitting potential of Z3CN20.09M DSS specimens became less positive with the increase of thermal ageing temperature from $350{ }^{\circ} \mathrm{C}$ to $500{ }^{\circ} \mathrm{C}$. While, the $E_{\mathrm{p}}$ values of thermally aged SAF2205 and SAF2507 specimens decreased first and reached the lowest level at 450

Table 2. EIS-fitted values of three DSS specimens in $0.5 \mathrm{~mol} \mathrm{~L}^{-1} \mathrm{NaCl}$ solution.

\begin{tabular}{lccccc}
\hline Thermal ageing temperature $/{ }^{\circ} \mathbf{C}$ & Specimen & $\mathbf{R}_{\mathbf{s}}$ & CPE-T/Fcm $^{2}$ & CPE-n & $\mathbf{R}_{\text {ct }}$ \\
\hline 350 & SAF2507 & 2.915 & $1.5715 \mathrm{E}-5$ & 0.88786 & 50962 \\
& SAF2205 & 3.294 & $1.6296 \mathrm{E}-5$ & 0.88231 & 44501 \\
& Z3CN20.09M & 2.299 & $1.4894 \mathrm{E}-5$ & 0.87936 & 40868 \\
450 & SAF2507 & 1.038 & $2.0828 \mathrm{E}-5$ & 0.79139 & 6097 \\
& SAF2205 & 2.227 & $1.9945 \mathrm{E}-5$ & 0.82435 & 16973 \\
500 & Z3CN20.09M & 1.878 & $2.2600 \mathrm{E}-5$ & 0.87976 & 26694 \\
& SAF2507 & 2.664 & $1.8811 \mathrm{E}-5$ & 0.85555 & 7786 \\
& SAF2205 & 2.040 & $2.0609 \mathrm{E}-5$ & 0.85175 & 19445 \\
& Z3CN20.09M & 2.375 & $1.8056 \mathrm{E}-5$ & 0.85509 & 24127 \\
\hline
\end{tabular}


${ }^{\circ} \mathrm{C}$ and then increased slightly with increasing ageing temperature.

(2) EIS results of three DSS specimens are coincident with the potentiodynamic polarisation testing results. The changes in the charge transfer resistance of SAF2205, SAF2507 and Z3CN20.09M specimens that affected by thermal ageing temperature are the same as the $E_{\mathrm{p}}$ values variation. It can be concluded that the resistance to pitting of $\mathrm{Z3CN} 20.09 \mathrm{M}$ specimen thermally aged at $500{ }^{\circ} \mathrm{C}$ is the worst, however the worst happening of pitting corrosion is found in SAF2205 and SAF2507 specimens aged at $450{ }^{\circ} \mathrm{C}$. There is little influence of low temperature (below $350{ }^{\circ} \mathrm{C}$ ) on the resistance to pitting of SAF2205 and SAF2507 DSS. But, the pitting resistance of them degrades drastically ageing at higher temperature above $450{ }^{\circ} \mathrm{C}$.

(3) The precipitation of Cr-rich $\alpha^{\prime}$ phases in ferrite and the formation of $\mathrm{Cr}$-depleted zones around $\alpha^{\prime}$ phases induced by thermal ageing is the main reason for the deterioration in pitting corrosion. The higher the ageing temperature, the more the $\alpha^{\prime}$ phases and Cr-depleted zones, thus the pitting resistance of SAF2205, SAF2507 and Z3CN20.09M specimens became poor when they were thermally aged at from room temperature (unaged) to 450 ${ }^{\circ} \mathrm{C}$. The further decrease in pitting potential of Z3CN20.09M specimens attributed to the precipitation of considerable $\mathrm{G}$ phases and a few $\mathrm{M}_{23} \mathrm{C}_{6}$ carbides.

(4) Pitting potential of SAF2205 and SAF2507 specimen thermally aged at $500{ }^{\circ} \mathrm{C}$ became little more positive than that of them thermally aged at $450{ }^{\circ} \mathrm{C}$ due to a healing or desensitization process, which is caused by the chromium diffusion reducing or eliminating the gradient of concentration of this element and the interface of $\mathrm{Cr}$-enrich $\alpha^{\prime}$ phase and $\mathrm{Cr}$-depleted zone. Although considerable $\mathrm{G}$ phase can form in the thermally aged SAF2205 and SAF2507 specimens at $500{ }^{\circ} \mathrm{C}$ too, the degradation of pitting corrosion resistance owing to the $\mathrm{G}$ phases does not enough to smooth the recovery of pitting resistance induced by the healing of thermal ageing.

\section{Acknowledgments}

This work was supported by the National Natural Science Foundation of China under Grant [numbers 51501001, 51604002]; Anhui Provincial Natural Science Foundation under Grant [number 1508085QE102].

\section{References}

1. Gunn RN. Duplex Stainless Steels: microstructure, properties and applications. Cambridge: Woodhead Publishing; 1997.

2. Lo KH, Shek CH, Lai JKL. Recent developments in stainless steels. Materials Science and Engineering: R. 2009;65(4-6):39-104.

3. Rovere CAD, Santos FS, Silva R, Souza CAC, Kuri SE. Influence of long-term low-temperature aging on the microhardness and corrosion properties of duplex stainless steel. Corrosion Science. 2013;68:84-90.

4. Olsson COA, Landolt D. Passive films on stainless steels-chemistry, structure and growth. Electrochimica Acta. 2003;48(9):1093-1104.

5. Wang YQ, Li N. Effect of ferrite on the precipitation of $\sigma$ phase in cast austenitic stainless steel used for primary coolant pipes of nuclear power plants. Materials Research. 2017;20(6):1690-1696.

6. Tranchida G, Clesi M, Franco FD, Quarto FD, Santamaria M. Electronic properties and corrosion resistance of passive films on austenitic and duplex stainless steels. Electrochimica Acta. 2018;273:412-423.

7. Mathew MD, Lietzan LM, Murty KL, Shah VN. Low temperature aging embrittlement of CF-8 stainless steel. Materials Science and Engineering: A. 1999;269(1-2):186-196.

8. Sahu JK, Kruppc U, Ghosh RN, Christ HJ. Effect of $475^{\circ} \mathrm{C}$ embrittlement on the mechanical properties of duplex stainless steel. Materials Science and Engineering:A . 2009;508(1-2):1-14.

9. Wang YQ, Han J, Yang B, Wu HC, Wang X. Precipitation behavior of the intermetallic phases in Z3CN20.09M stainless steel for primary coolant pipes of nuclear. Acta Metallurgica Sinica. 2013;49(4):415-420.

10. Li S, Wang Y, Wang X, Xue F. G-phase precipitation in duplex stainless steels after long-term thermal aging: a high-resolution transmission electron microscopy study. Journal of Nuclear Materials. 2014;452(1-3):382-388.

11. Chandra K, Singhal R, Kain V, Raja VS. Low temperature embrittlement of duplex stainless steel: Correlation between mechanical and electrochemical behavior. Materials Science and Engineering: A. 2010;527(16-17):3904-3912.

12. Iacoviello F, Casari F, Gialanella S. Effect of " $475{ }^{\circ} \mathrm{C}$ embrittlement" on duplex stainless steels localized corrosion resistance. Corrosion Science. 2005;47(4):909-922.

13. Wang YQ, Li D, Sun L, Li N, Liu M, Shen W, et al. Pitting corrosion of thermally aged cast duplex stainless steel for primary coolant pipes of nuclear power plants. Corrosion Engineering, Science and Technology. 2017;52(6):447-452.

14. Frankel GS. Pitting corrosion of metals: a review of the critical factors. Journal of the Electrochemical Society. 1998;145(6):21862198.

15. Lv JL, Liang TX, Dong LM, Wang C. Influence of sensitization on microstructure and passive property of AISI 2205 duplex stainless steel. Corrosion Science. 2016;104:144-151.

16. Ryan MP, Williams DE, Chater RJ, Hutton BM, McPhail DS. Why stainless steel corrodes. Nature. 2002;415(6873):770-774.

17. Boucherit $\mathrm{N}$, Goff $\mathrm{AHL}$, Joiret $\mathrm{S}$. Influence of $\mathrm{Ni}, \mathrm{Mo}$, and $\mathrm{Cr}$ on pitting corrosion of steels studied by raman spectroscopy. Corrosion. 1992;48(7):569-579. 
18. Wang YQ, Li N, Yang B. Effect of ferrite on pitting corrosion of $\mathrm{Fe} 20 \mathrm{Cr} 9 \mathrm{Ni}$ cast austenite stainless steel for nuclear power plant pipe. Corrosion Engineering, Science and Technology. 2015;50(4):330-337.

19. Zhang LH, Zhang W, Jiang YM, Deng B, Sun DM, Li J. Influence of annealing treatment on the corrosion resistance of lean duplex stainless steel 2101. Electrochimica Acta. 2009;54(23):5387-5392.

20. Park CJ, Kwon HS. Effects of aging at $475{ }^{\circ} \mathrm{C}$ on corrosion properties of tungsten-containing duplex stainless steels. Corrosion Science. 2002;44(12):2817-2830.

21. Yi YS, Shoji T. Detection and evaluation of material degradation of thermally aged duplex stainless steels: electrochemical polarization test and AFM surface analysis. Journal of Nuclear Materials. 1996;231(1-2):20-28.

22. Park JS, Yoon YK. Evaluation of thermal aging embrittlement of duplex stainless steels by electrochemical method. Scripta Metallurgica et Materialia. 1995;32(8):1163-1168.

23. Berg HP. Corrosion mechanisms and their consequences for nuclear power plants with light water reactors. Reliability and risk analysis: theory and applications. 2009;2:57-68.

24. Chandra K, Kain V, Raja VS, Tewari R, Dey GK. Low temperature thermal ageing embrittlement of austenitic stainless steel welds and its electrochemical assessment. Corrosion Science. 2012;54:278-290.

25. Hättestrand M, Larsson P, Chai G, Nilsson JO, Odqvist J. Study of decomposition of ferrite in a duplex stainless steel cold worked and aged at $450-500{ }^{\circ} \mathrm{C}$. Materials Science and Engineering:A. 2009;499(1):489-492.
26. Almanza E, Murr LE. A comparison of sensitization kinetics in 304 and 316 stainless steels. Journal of Materials Science. 2000;35(13):3181-3188.

27. Tavares SSM, Terra VF, Lima Neto P, Matos ER. Corrosion resistance evaluation of the UNS S31803 duplex stainless steels aged at low temperature $\left(350\right.$ to $\left.550^{\circ} \mathrm{C}\right)$ using DLEPR tests. Journal of Materials Science. 2005;40(15):4025-4028.

28. Ahn YS, Kim JM, Jeong BH. Effect of aging treatments and microstructural evolution on corrosion resistance of tungsten sbustitued 2205 duplex stainless steel. Materials Science and Technology. 2002;18(4):383-388.

29. Wang YQ, Yang B, Han J, Wu HC, Wang X. Effect of precipitated phases on the pitting corrosion of Z3CN20.09M cast duplex stainless steel. Materials Transactions. 2013;54(5):839-843.

30. Ilevbare GE, Burstein GT. Role of alloyed molybdenum in the inhibition of pitting corrosion in stainless steels. Corrosion Science. 2001;43(3):485-513.

31. Pardo A, Merino MC, Coy AE, Viejo F, Arrabal R, Matykina E. Pitting corrosion behaviour of austenitic stainless steels combining effects of Mn and Mo additions. Corrosion Science. 2008;50(6):1796-1806.

32. Deng B, Jiang YM, Gong J, Zhong C, Gao J, Li J. Critical pitting and repassivation temperatures for duplex stainless steel in chloride solutions. Electrochimica Acta. 2008;53(16):5220-5225.

33. Lo KH, Kwok CT, Chan WK, Zeng D. Corrosion resistance of duplex stainless steel subjected to long-term annealing in the spinodal decomposition temperature range. Corrosion Science. 2012;55:267-271. 